\title{
The International Conference on Metrology of Environmental, Food and Nutritional Measurements (MEFNM2008)
}

\author{
P. Charlet
}

Received: 27 March 2009/Accepted: 30 March 2009/Published online: 8 April 2009

(C) Springer-Verlag 2009

The International Conference on Metrology of Environmental, Food and Nutritional Measurements (MEFNM2008) was held on 9-12 September 2008 in Budapest, Hungary.

This Conference organized under the auspices of the International Measurement Confederation (IMEKO) involved the Hungarian Chemical Society (MKE) and the Hungarian Scientific Society of Measurement, Automation and Informatics (MATE).

The MEFNM 2008 gathered three parallel scientific events: the 2nd IMEKO TC19 Conference on Environmental Measurements, the 1st IMEKO TC23 Conference on Food and Nutritional Measurements and the 1st IMEKO TC 24 Conference on Chemical Measurements. TC19, TC23 and TC24 are the newest technical committees (TC) of IMEKO.

The three sessions were organised and chaired by Pedro Silva GIRAO, Chair of IMEKO TC 19, Portugal; Venkatesh IYENGAR, Chair of IMEKO TC 23, USA; and Philippe CHARLET, Chair of the IMEKO TC 24, France. Founding members of both TCs, recognizing the common interest and synergy between their fields of activity, decided to provide an international platform of effective collaboration in analytical chemistry, aiming to improve the reliability, comparability and traceability of chemical measurements in a large numbers of sectors, addressing industrial and monitoring laboratories needs and on site measurements. MEFNM 2008 has been successful in offering such a forum for the representatives of research, education and industry to meet and exchange ideas about technologies and applications, in two important fields: environment and food and nutritional measurements.

The conference highlighted the inter-linkages between metrology in chemistry as applied to specific groups of measurements in environment, food and nutrition. One important objective was to communicate to application fields (environment and food sectors) the concepts of metrology in chemistry.

Two papers presented during MEFNM are included in this issue. Both papers were of great interest to the audience by demonstrating the role of National Metrology Institutes in proficiency testing schemes (by providing the reference value and reference materials) and improving the knowledge of organometallic species which play an important role in the environment and health sectors.

P. Charlet $(\bowtie)$

Laboratoire national de métrologie et d'essais,

29 avenue Hennequin, 78197 Trappes Cedex, France

e-mail: Philippe.charlet@lne.fr 